Témoigner Témoigner. Entre histoire et mémoire

Getuigen Revue pluridisciplinaire de la Fondation Auschwitz

$126 \mid 2018$

Questions sur l'avenir du travail de mémoire

\title{
Oorlogskinderen in België: een gesprek met Gerlinda Swillen
}

Het gesprek werd gevoerd door Yannik van Praag (Daniel Weyssow was aanwezig tijdens het interview)

Enfants de guerre en Belgique. Entretien mené par Yannik van Praag

(avec la participation de Daniel Weyssow)

\section{Yannik van Praag}

Traducteur : Rita Roggen

\section{CpenEdition}

Journals

Édition électronique

URL : https://journals.openedition.org/temoigner/7090

DOI : $10.4000 /$ temoigner.7090

ISSN : 2506-6390

Cet article est une traduction de :

Enfants de guerre en Belgique - URL : https://journals.openedition.org/temoigner/7078 [fr]

\section{Éditeur :}

Éditions du Centre d'études et de documentation Mémoire d'Auschwitz, Éditions Kimé

Édition imprimée

Date de publication : 2 avril 2018

Pagination : 24-29

ISBN : 978-2-930953-06-9

ISSN : 2031-4183

Référence électronique

Yannik van Praag, «Oorlogskinderen in België: een gesprek met Gerlinda Swillen», Témoigner. Entre histoire et mémoire [Online], 126 | 2018, Online op 20 janvier 2022, geraadpleegd op 04 février 2022. URL: http://journals.openedition.org/temoigner/7090 ; DOI: https://doi.org/10.4000/temoigner.7090 


\section{OORLOGSKINDEREN IN BELGIË: EEN GESPREK MET GERLINDA SWILLEN}

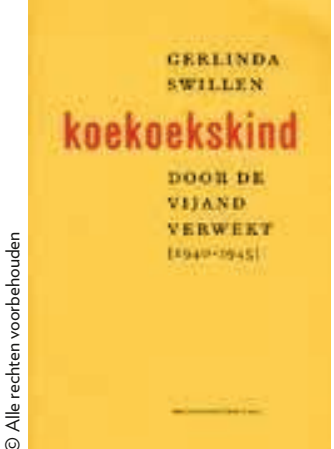

INTERVIEW Gedurende de Tweede Wereldoorlog werden in België duizenden kinderen geboren uit een relatie tussen militairen van de Wehrmacht en autochtone vrouwen. Het zijn oorlogskinderen in de letterlijke betekenis van het woord. Hun ouders zouden elkaar niet hebben ontmoet zonder het conflict. Gerlinda Swillen is een van die kinderen. Als ze in 2007 eindelijk te weten komt wie haar heeft verwekt, gaat ze nog meer energie aan de dag leggen om haar verleden te leren kennen. Dit speurwerk leidt tot een eerste echte studie over oorlogskinderen in België en wordt bekroond met een doctoraat, dat werd verdedigd in januari 2016.

$\rightarrow$ Het gesprek werd gevoerd door Yannik van Praag (Stichting
Auschwitz)! Auschwitz)!

Kunt u ons eerst uw persoonlijke verhaal vertellen, zoda we uw initiatief en onderzoek beter kunnen begrijpen?

Gerlinda Swinnen : Zolang ik denken kan, heb ik vermoed dat mijn werkelijke roots niet die waren die men aangaf. Er klopte iets niet. Ik had het gevoel - of veelee kw - dat nen deijel or Ik ben met die twiflopgen om elk teken en elke stilte op te vangen, ik legde mij oor te luisteren als ik onderonsjes ontwaarde, ging in

Mijn moeder was een kleuteronderwijzeres met een diploma van de normaalschool van Brugge. Ze wa de eerste en enige leerlinge die de lessen zedenleer ord her zeerd door de katholieke meerderheden en dus was werken in Dutsland mar ze buiten het onderwijs zoeken Ze vond een plan bouvernante in Gent in een rijke familie uit de textieouvernante in Gent, in een rijke familie uit de textie-

(1) Daniel Weyssow was aanwezig tijdens het interview lindustrie, die vooral van zich zou laten horen omwille van economische collaboratie.

Dan ontmoette ze een onderofficier van de Wehrmacht en geraakte ze zwanger. Er werd een huwelijk gepland, maar kennelijk heeft haar vader er zich tegen verzet. Toen has zwangerschap zichtbaar werd, werd ze weggestuurd en ging ze weer in Oostende wonen. Bij haar ouders, mijn grootouders. Daar beviel ze in

Niet veel later kreeg ze werk als gouvernante in Brussel. Vooral mijn grootouders hielden zich met mij bezig tot ik drie jaar was. Ik was immers een natuurlijk kind. Ik droeg op dat ogenblik de naam van mijn ik dat ik in een normal gezin opgroeide en dach ik dat ik in een normaal gezin opgroeide en dat mijn groton mijn oom mijn broer (hij was man dus mijn zus en mijn oom mijn broer (hij was maar twee jaar zone) was had mijn moer zone) was had nijn moeder een speciale vergunning nodig om ons te komen bezoeken en die was moeilijk

Mijn verwekker wist dat ik geboren was. Hij heeft mijn voornaam mee gekozen. Een Duitse wet verplichtte om Germaanse namen te kiezen. Mijn moe derwilde Gerd het Gerlinda lange tijd Linda genoemd, maar rond de leeftijd van 16 jaar heb ik duidelijk gevraagd om mijn juiste voornaam te gebruiken. In 1946 huwde mijn moeder een weduwnaar, vader van een jong kind. Die man erkende mij en sindsdien draag ik zijn naam: Swillen.

Zoals ik al zei, zijn de oorlogskinderen meesters in de kunst van het ontdekken van de kleinste aanwijzin in elk stilzwijgen, in de minste vluchtige uitdrukki op een gezicht... In mijn geval snel over in zekerheid, onder andere wanneer ik twee oud tje - dat van het huwelijk van je - dat van het huwelijk van 'gewettiod kind' gewettigd kind'.

Mijn wettelijke vader ${ }^{2}$ werkte in een bedrijf met een sterke katholieke verankering. Ik heb mijn eerste communie gedaan, het als mijn 'broer'. Mijn moeder heeft er altijd voor gezorgd dat wij doorgin-

ij leefden gedurende enige tijd in Brussel. Ik ging naar de Franstalige kleuterschool in de rue Mommaerts huisden we noar Gent, war huisden we naar Gent, waar ik mijn lager onderwijs doorliep. Door onze talrike verhizingen (Oostende, Brussel, Gent) familie buiten onze naaste familie niemand nog ons verale positie vanische ensociale positie van het gezin ging er gedurende die naoorlogse ik naer de univeriteit Toen ik naar de universiteit wilde gaan om er Germaanse te stu-

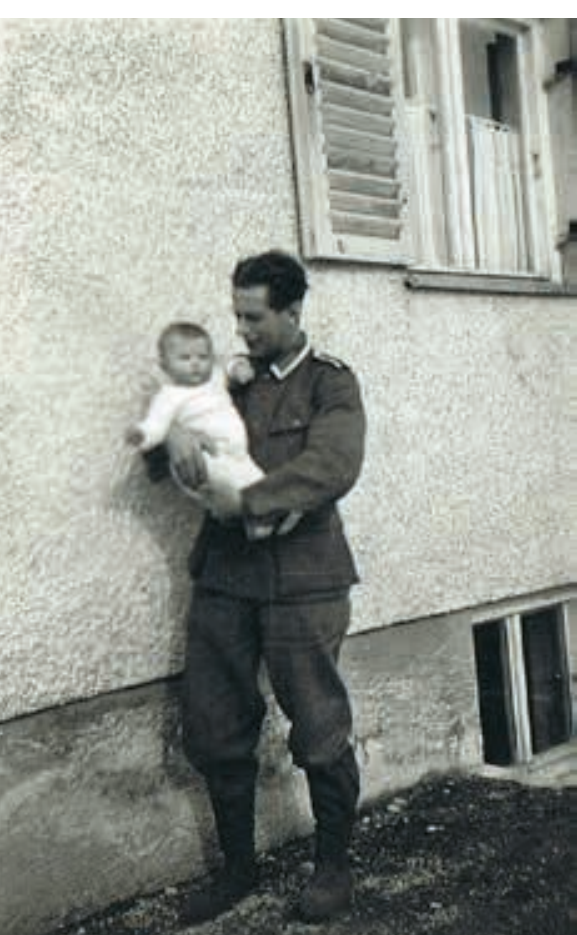

Karl Weigert met de zus van Gerlinda, dith, geboren in juli 1943. Zij is eveneens een in het noorden van Frankrijk ontmoette haar moeder had geweigerd met hem te huwen. peurwerk en de inlichtingen die ik bij mijn familie had kunnen bijeensprokkelen, mij ondertussen zekerhei geven. Zonder de naam van mijn verwekker kon ik zijn ijn mo . ' (T) 'Tochwel Ikken die!'Op mijn $65^{\circ}$ heb ik mijn 65 heb ik dan vernomen Karl Weigert.

Stortte u zich damameteen op uw speurwerk?

Ja! Nu mijn verwekke een naam had, kon ik effectie beginnen aan mijn zoektocht. Ik schreef naar Ceges (nu CegeSoma, Studie- en Documentatiecentrum Oorlog en Hedendaagse Maatschappij) waar directeur Rudi Van Doorslaer mij voorstelde om verder te gaan dan mijn persoonlijke verhaal. Ik aanvaardde zijn voorstel.

Wij deden een oproep naar getuigen met de hulp wat reacties, voornamelijk van Franstaligen uit Brussel en Wallonië. Eenjarr laterontvingen we vingen weeen reeks contacten via de Vlaamse pers, zodathet venwicht werd hersteld. Dat tot de publicatie van kind: door de vijand verwekt (2009), een verzand verwekt (2009), een verzameling va Ik studeerde van 1960 tot 1964 aan de ULB-VUB en werd al gedurende mijn studies in 1963 lerares in het werd algedurende nijn studes in 1963 lerares in het was altijd al mijn droom geweest. Ikbs a mijn drom geweest. Ik ben opgegroeid met die twijfels, dat mysterie da
rond mijn echte oorsprong hing, ook al hadden mijn

(2) Als Gerlinda spreekt over haar vader, bedoelt ze har wettelijke vader een zeventigtal verhalen. Ondertussen ging mij die ik in 2016 verdedigde en ot publiceerde: De wieg van WO II Oorlogskind eren op de as Bruseel-Berlijn van WO II, Oorlogskinderen op de as Brussel-Berlijn. somelijk eschiedkundigen hebben geopperd dat ik tegelijk onderzoekster en 'voorwerp van het onderkunnen hebben voor de objectiviteit va ni.j zou 
œ. Ik geef toe dat ik dezelfde twijfels had in het begin. Ik antwoordde hierop dat de getuigen die ik heb ontmoet, zich zeker niet helemaal hadden blootgegeven, als

Op nijn persethen

Op mijn persoonlijke zoektocht nam ik contac op met het Deutsches Rotes Kreuz (het Duitse Rode Kruis) en de Deutsche Dienststelle-WASt in Berlijn (een Duitsedien van de Tweede Wereldoorlog beheert). Daar vonden ze niets over mijn verwekker. Op een studiedag ove Wolfgang Wet te vergarn (de vader van mijn verk e ver een hoge functie bij de Deutsche Bundesbahn en zijn het dossier Karl Weigert heStaße in Munchen, werd het dossier Karl Weigert heropend. In augustus 2008 en man, geboren in 1903 (en dus ou man, geboren in moeder mijdeed geloven)enoverledenin 1958. Op mijn Jamilie Ik nam zelf contact op met de dienst die de eranilie. Ik nam zelf contact op met de dienst die de he en het werd onderhouden. Dat was het bewijs dat er nakomelingenwaren. Ik kreegvervolgenseen briefvan een zekere Kar Weigert, zijn zoon - mijn broer - samen met een foto van mijh verwekker! ik belde meteen die broer op, van wie ik net het bestaan vernam. Op dat in 'zussen': de vernam ook verder het bestaan van twee andere, Edith, woonde in Beieren en ging ikbezoek

\section{Duiken vaak gelijkaardige vragen op in de levensver-} halen die u hebt verzameld?

Ik heb onder andere geprobeerd om daarover verslag uit te brengen in mijn boek Koekoekskind. D boeken die nu verschijnen, zijn vooral autobiografieën, waarin men het hele verhaal van eén persoon krijgt. Het is geen verslag van de massa. Ik heb juist aan die veelheid een stem willon geven. Daarom ook heb ik ervoor geopteerd om mijn thesis in 2016 als een soort hele reeks vragen, en illustreert ze and han een frage reeks viagen, en illustreert ze aan de hand van fragmentenit intervis. In mijn thesis probeer iker antwoorden op te vinden en ik ga dieper in nieuwe en bestaande vragen die opdokengedurende mijn onder-
Het ondervragen van de kinderen is de kern van mijn werk. Vaak had men belangstelling voor de moeders en onvoldoende voor de kinderen. con en on concentreren op hún standpunt. In de meeste gevalinstemming zonder dat we die darom wederzijdse liefdening, zonder dat we die darom meteen als

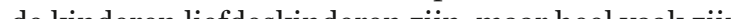
ze het gije vaak zijn zeit he teit, wilde de ver we overleven. I noem dat de kleine prostitutie. Uit de verhalen van mijn getuigen en de geraadpleegde reniever ren werden geboren als gevolg van een verkrachting. van het overige heb ik zeer weinig gevallen ontmoet van moeders die w

neel belang gehecht aan het opmaken van een profiel van de vaders. En dat is uniek. Het verlangen naar het vaderschap, de wens om vader te n, wordt maar al te vaak miskend. En toch gebeurde het niet zelden dat een vader nieuws of een foto vroeg, soms zelfs dat vrouw en kind bij zijn gezin in Duitsland kwamen wonen, wat de nationaalsocialistische autotheiten om demografische redenen en met het oog op de 'nazificering' zelfs stimuleerden.

Welk type geschreven bronnen zijn nuttig gewees voor uw onderzoek?

Dat zijn er heel veel. Een basisdocument in dit onderzoek is de geboorteakte. Die is essentieel. Het is het bewijs dat het kinde. Die is essentieel. Het geboorteakte heeft geboorteakte heeft geen nationaliteit, geen juridische bescherming... Het bestaat niet! Er zijn veel mogelijke bronnen. Administratief, zoals de geboorteregister bijventer of juridisch, bijvooberd de ste aanleg, ondat sommige vonnissen, meer bepaald in het geval van adoptie, de waarde kunnen hebben van

Ik heb me eveneens gebogen over wat ik de 'speciale gevallen" noem, waarbij hoogstwaarschijnlijk een groot aantal Joden horen. In sommige registers voor de bevestiging van voogdijsch men aanvragen voor de bevestiging van voogdjschap na de oorlog. Op het moment zelf, gedurende de bezetting, wa a neter geboorten moest doorgeven aan de vrederechter met opzet heeft verzuimd deze door te geven, dan wel of de rechter heeft beslist deze 'dossiers' niet te vervolgen. Was het om geen aandacht te vestigen op de kindere en ze op die manier te beschermen? Het is een piste or het ogenblik heb ik daaro

thet bant heb ik drie gevallen van kindermoord gevonden was en in een ander geval een lid van de geallitair was en in een andergevalen lid van de geallieer

De archieven van het OCMW van de stad Brussel waren zeer nuttigvoor mij. Het Sint-Pietersziekenhui die werden beschourd als heteigendom van de ats,

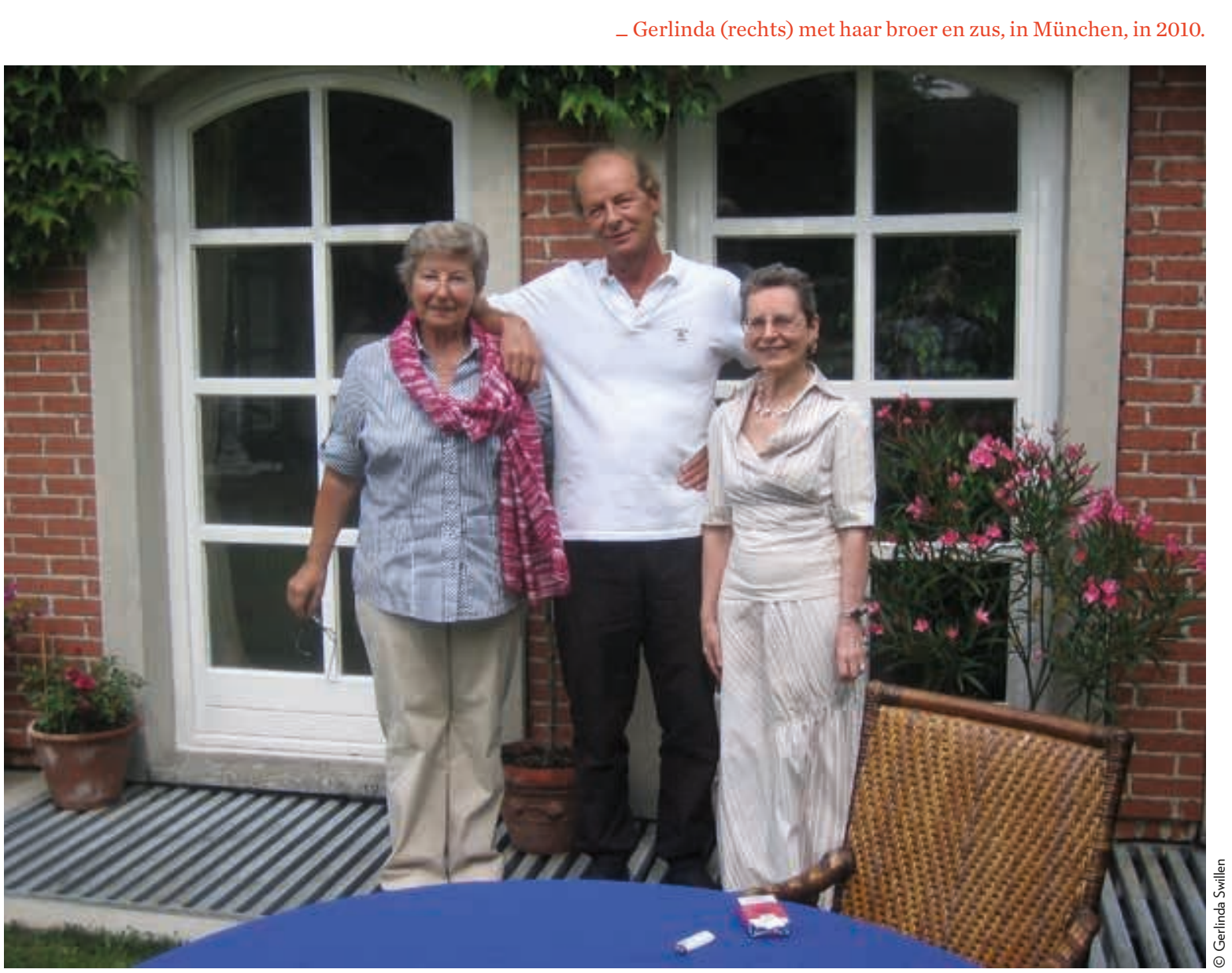

maar er zijn wel de inkomende en uitgaande registers. De dossiers van de Stichting Lambert trokken evenens mijn aandacht. Daarin wordt periodiek melding gemaakt van curettages. Die waren het gevolg van Er is een piekin twee periodes:indenasleep van deerte ence de een aantal van deze curettages abortussen verbergen, is reerd word rieerd word. relevante militair Ditse

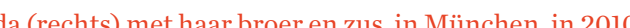

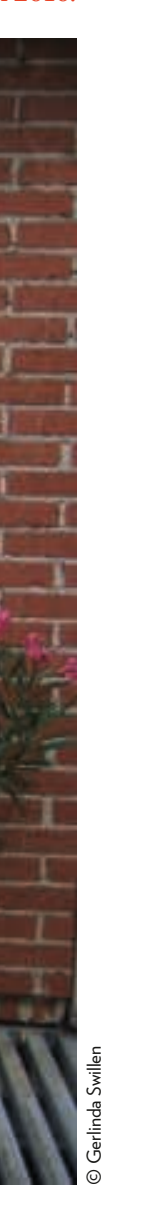
gyrolonis 
•• gerekruteerd in 1940 en die België is gepasseerd, daarna naar het Oostfront trok en vervolgens terugkwam naa Frankrijk, heeft aangetoond hoeveel een passage aa heeft veranderd. Ze waren brutaler geworden.

De geschiedenis van het ziekenhuis Brugmann i ook interessant. Dat werd in mei 1940 opgeëist door de Wehrmacht om Kregslazett te word, Br werden dus Duitse militairen ondergebracht, maar het blijkt dat ook oorlogsgevangenen, patiënten van andere instelingen van de bezetter, en burgers er verbleven.

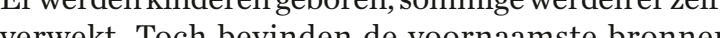
vet met betrekking tot het ziekenhuis Brugmann zich in Berlijn. Niet alleen voor mij, maar met name voor de oorlogskind de kile op zoek zijh naar hun verwekker, angezien de kinderen die er geboren werden, vaak Soms werden ze net ijn anger lijke weden ze niet eens aangegeven bij een burgerlijke stand. Hoeveel kinderen zijn er op die manier verdwenen tussen de plooien van de geschiedenis?

De archieven van het OCMW an Brussel bevat-

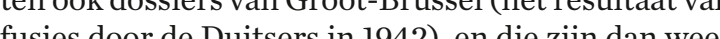
fusies door de Duitsers in 1942), en die zijn dan weer interessant voor het Institunt Jules Bordet dat evenens door de bezetter was opgeëist en bestemd voor die over de in o

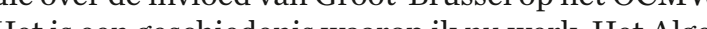
ret is een geschic ne warije meen Rijksarchief bevat talijke juridische bronnen, maar ook de archieven van de Duitse ambassade in lk kn her hante doc In Duals

In Duitsland zijn er vanzelfsprekend talrijke bronnen. Er is de Deutsche Dienststelle waarover ik het bij. over de stang, opgericht in 1939, houdt de dossiers buiter de staat van dienst van de militairen van het Durtse leger tijdens de Tweede Werclon. Na 1945 speelde deze dinst een belangrijke sociale rolvoor de oorlogsweduwen en -wezen. Het is een centrale plaats Jur jaar behandelt de die op zongek zijn nar hur ven van Ook de medische archieven van de Wehrmachtwer. dor verzmeld en op di manier heb ik de arhieven daar verzameld en op die manier heb ik de archieven Fretrekng to collecties van de Deutsche Diens oulle zullen. De worden geïntegreerd in de centrale nationale archievan Duitsland (Bundesarchiv).

In Berlijn bezit het Landesarchiv Berlin nog steed interessante bronnen met betrekking tot de Belgische arbeiders in Berlijn, maar ook juridische archieven. Ik heb eveneens de archieven van de Humboldt-universiteit van Berlijn geconsulteerd. Die deed de administrativan LaCharité, een universiteitsziekenhuiswaa Belgische vrouwen zijn bevallen. Enkele getuigen die ik sprak, werden daar geboren. Ik heb hun sporen in
de archieven teruggevonden.

\section{Bij uw onderzoek bent u onvermijdelijk in aanraking} gekomen met de kwestie Lebensborn.

De kwestie Lebensborn e.V., een SS-creatie van Himmler (voor België betreft die het tehuis Ardennen in Wégimont), werd uitgespit, vooral door de sensatiepers. De kraamkliniek in Wolvertem daarentegen, die en creatie was van de National Sozialistische Volkswohlfahrt onder de Duitse minister Conti, is nauwelijk bekend, buiten uit het onderzoek van dr. Yves Louis. De kraamkliniek werkte nauw samen met het Kriegslazarett Brugmann, maar richtte zich eerder tot de Duitse kolonie in Belgiè en de vrouwelijke hulpkrachten van de Wehrmacht. Achter Lebensborn vindtmen dezelfde logica als achter de discrete bevallingen in bepaalde katholieke instellingen voor ongeh wa of anonieme moeders - in Frankrijk accouchement sous $X$ - en een identieke mentaliteit van schaamte en hypocrisie die de basis vormt van de verschillende actuele wetsvooris de bedoeling om de 'fout' van ete bevalling. Het is de bedoeling om de fout van een buitenechtelijke seksuele relatie van een vrouw te verbergen en hun kershil is enkel dat het kind voor de Lopteren. Het

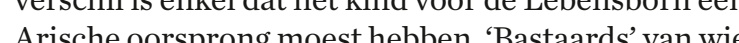
Arische oorsprong moest hebben. 'Bastaards' van wie werd aangenomen dat ze 'raszuiver' waren, werden er annaard, ook al bleek het haast onmogelijk om de vader te achterhalen. Hun ontwikkeling volgens de Ari-

Erwaren vershillende roglijkhedecontroer. Er waren verschillende mogelijkheden voor de kinderen van de mannen van de Lebensborn. Sommige verbleven er enkel tot hun moeder werk vond, andere werden geadopteerd. In dat geval tekende de moede gaf voor adoptie. Duitsers gingen na of het kind vrij'in voor adoptie. Duitsers gingen na of die kinderen in aannerking kwannen voor aloptie. Als dat zo was,
Sommige kinderen die 'niet in aanmerking kwamen voor adoptie' werden vermoedelijk naar concentra(lekanpen Moet er nog veel werk gebeuren met betrekking to
de

Er moet nog reusachtig veel werk gebeuren: in Italië is niets gebeurd, in Griekenland nauwelijks iets en dat geldt ook voor Oost-Europa bijvoorbeeld. In Belgie spren oologskideren. Twintigduizend, veertigduizend? Het is nauwelljks te schatten. Maar die discussies over cijfers lijken me van ondergeschikt belang.

De essentie ligt elders. Vaak reduceert men de geschiedenis van de Tweede Wereldoorlog tot drie grote themas. decllaboratie, de repressie en de depotatie. De Kwestie van het herstel, hclusief het psychologische en sociale herstel, is cruciaal, maar wordt vaa over het hoofd gezien. Ik heb het trouwens niet allee over de Tweede Wereldoorlog. Oor grkinderen zijn mee zij te kampen hebben, zijn vreselijk actueel.

Daarbij aansluitend de volgende vraag: $u$ hebt ook geinnvesteerd in netwerken en verenteren,

Toen ik vernam dat er een netwerk van oorlogskinderen bestond in Berlijn, heb ik contact met he opgenomen en wij hebben beslist om een formelere vereniging te stichten: het netwerk BOW.i.n. (Born Of War international network). Ik was de eerste woordvoerdervan 2009 tot 2013 . Het netwerk bestaat uit ee Deense, een Noorse, een Finse, twee Franse verengingen (o.a. Cœurs sans frontières die zich eveneen den geboren), een Belgischevereniging (mar die heeft den geboren), een Belgisch nooit echt gewerkt), evenals een Duitse vereniging van

Het voornaamste doel van BOW.i.n. is effectieve erkenning, een echt statuut en een bescherming voor de oorlogskinderen de bedoeling om de wonden uit het verleden te helen, maar wettelijke en concrete antwoorden te krijgen voor alle kinderen die vandaag worden geboren en worcor kennen van hun verwekker, met het logische gevolg dat toegang moeten krijgen tot de relevante archieven. lk zou willen dat dese stappen in eerste instantie wo Europese impuls zijn om to de EU druk absoluut een uro zet, zet, zal een list als Japan volgen. En opnieuw: deze Wereldijt natuurijk niet beperkt tot de Tweede Wereldoorlog. Elke oor log genereert oorlogskinderen: kinderen geboren in Indonesie of in China met n val... End zajn den veboren in de kolonies. De crisissen en conflicten van vandaag de dag dragen er jammer genoeg toe bij
dat de kwestie actueel blijft. 